\title{
National Bibliography and Bibliographical Control: A Symposium
}

\begin{abstract}
N THE April 1947 issue of College and Research Libraries the "Recommendations Adopted by the Conference on International Cultural, Educational, and Scientific Exchanges, Princeton, N.J., Nov. 26, 1946" were published. One of the important recommendations was the development of a complete current national bibliography. Because of the importance of this problem, the editors print below a paper on "National Bibliography and Bibliographical Control," by Paul Vanderbilt, of the Library of Congress staff, together with an introductory memorandum by Luther H. Evans, Librarian of Congress. There are also included comments by Theodore Besterman, Jerome K. Wilcox, and Rebecca Rankin. Since there are various aspects of the proposal which are not covered in the remarks of the commentators, it is suggested that readers having viewpoints other than those expressed here send them to the editor. It may be possible to publish them in a subsequent issue.
\end{abstract}

\section{Introductory Memorandum ${ }^{1}$}

I. I attach hereto a memorandum entitled "National Bibliography and Bibliographical Control" prepared by Paul Vanderbilt of the staff of the Library of Congress.

2. This memorandum has been prepared in direct response to the resolution adopted at the Conference on International Cultural, Educational, and Scientific Exchanges, Princeton, N.J., Nov. 26, 1946, as follows:

It is recommended that the Library of Congress should formulate and present to A.L.A., A.R.L., S.L.A., and other library associations in this country, for their comment and criticism, plans for editing and publishing a complete current national bibliography of the United States, involving as may be necessary the coordination of existing efforts in this field, such as the catalogs of the Superintendent of Documents, the Monthly Checklist of State Publications, Cumulative Book Index, Catalog of Copyright Entries, and other sources, and looking to the coverage of fields not now covered, such as municipal documents, house organs, etc.

and pursuant to the decision, taken at the meeting on Jan. 22, 1947 to follow up on the

1 Originally addressed to Carl H. Milam, Executive Secretary, American Library Association.
Princeton conference, that the Library of Congress would accept the job, and would have something ready for comment and criticism at the June meeting of A.L.A. at Atlantic City.

3. As you know, the discussions regarding "bibliographical control of research materials" go back as far as does the need for it. In the very recent past there have been the extensive discussions and researches of the joint Committee on Indexing and $\mathrm{Ab}$ stracting in the Major Fields of Research, representing io libraries and other professional associations, which, in its final report in 1945 recommended that coordination of bibliographical activity be recognized as a function of the federal government. In the more recent past we have seen, in the suggestions submitted for the program of UNESCO, that the crying need of intellectual workers throughout the world is the information regarding the published materials within their respective fields of research. Most recent, of course, we have the action of the Princeton conference. But the instances which I cite are merely indicative and symptomatic of a universal need. 
4. Mr. Vanderbilt's paper is the first essay toward the development of a genuinely comprehensive plan to meet this need. In no sense does it attempt to provide all, or even a large number, of the answers. It does, however, attempt to strike at the root of the problem and to provide a fundamental answer. It cannot, in any sense, be taken to represent the official and final opinion of the Library of Congress; nor is it to be assumed that the Library of Congress is prepared to execute the plan which is projected. In brief, Mr. Vanderbilt's paper is an attempt to formulate a proposal for basic bibliographical control of the materials of research-basic in the sense that, once done it would not have to be repeated, and also in the sense that further bibliographical activity might be developed on a basis of it.

5. I hope that the paper may be read and discussed in this light. As I have said above, it does not presume to give all, or even a large number, of answers. It does not, for example, tell us whether we should give up the separate publication of the Catalog of Copyright Entries or of the Monthly Checklist of State Publications. It does not tell us whether the catalog should separate books from music and maps, or list them together; whether official publications should be arranged with belles-lettres or separated therefrom. And, if it does not give us the answers regarding our own bibliographical publications or our own bibliographical procedures, it is much further from providing answers with regard to publications or procedures which are not our own.

6. We hope for discussion of the basic principle. We hope for criticism. We hope for suggestions, however wild or ideal. We propose to go on from this statement to a convincing and-we hope-a practicable cooperative plan. Luther $H$. Evans Librarian of Congress.

\section{National Bibliography and Bibliographical Control}

$\mathrm{I}^{\mathrm{N}}$ N THE Library of Congress, we have been talking among ourselves for a long time about bibliographical controls. We haven't always called it that, or even bibliographical planning, a term which we used in connection with setting up a specific project for investigation. This project has been envisaged in several different ways. As a possible future staff appointment, it was described in terms of need for an energetic and imaginative person to develop and coordinate the bibliographical services rendered by the library to the other libraries of the nation, through card distribution, through the union catalog, through bibliographical and reference service, and through interlibrary loans, to plan an expanded service program for the library as a whole, and supervise its execution. As something more preliminary, it has been discussed in terms of someone who would travel and talk to librarians and others throughout the country, exploring the achievements already reached and the plans in mind, with a view to gaining an adequate measurement of professional thinking as well as details of actual accomplishment. In still other preparatory terms, we have thought of collecting data on what has already been written on the integration of bibliographical controls, with special reference to specific plans so that they can be compared, and compiling lists of individuals, committees, and organizations known to be working, not necessarily on individual bibliographies but rather on the coordination of all bibliographical effort. So far, our findings are that there is little unanimity of opinion, and no one who has given the matter any close observation or well-informed reflection will find this surprising.

There are two kinds of intensive activities stirring. There is impassioned urging that the mastery of recorded knowledge be considered as of such enormous importance as to underlie the future of peace, the future of research, and the future of practically every activity of mankind, and theoretical promising that this mastery will achieve through records the same accuracy of communication from mind to mind that conversation, the telephone, and the mails have already given us. The other kind of activity conjures up particular projects: to list periodicals accord- 
ing to their principal subject content, to establish uniform codes for citing the abbreviated titles of periodicals, to issue a union bibliography of publications in the field of international relations, to present a uniform code for cataloging books printed in $\mathrm{He}$ brew, to microcopy for preservation newspapers printed upon perishable paper, and so on almost ad infinitum. Those who hope for world accord and concerted action along the entire front of the struggle for control of recorded knowledge retire almost inevitably, in the end, behind a pious hope for a change in human nature, for the imposition of legal regulations, for spontaneous cooling of some of the hottest arguments known to the learned world, or possibly for the help of a superelectronic mechanical aid to thinking. The protagonists of limited, isolated schemes fare much better, and the great progress that has been made is due precisely to their unremitting, intensive energy in independent creative effort. Their trouble is mainly lack of funds. Most of these projects are expensive, and the amount of readily available money is insufficient to finance them all, so that competition inevitably prevails over rational selection.

With the announcement of UNESCO, many saw on the horizon a kind of international Rockefeller Foundation which, to those who come first, with the most appealing arguments, might be an ideal solution, but such hopefuls have often read the UNESCO documents without sufficient breadth of interpretation or possibly without sufficient care. UNESCO, like every other intelligent effort, is attempting to make known to one party what other parties are doing, to serve as a medium for the comparison of projects, in the hope that independent action all over the world, with the addition of an improved knowledge of similar efforts elsewhere, may become a little more effective, and that eventually there may develop a kind of common denominator, an expressed and well-understood point of departure.

The specific projects which yield the most valuable results are those which bear within them a common denominator, some part of a universal approach to the difficulties of bibliography as a whole. Our problem is "to find the comprehensive pattern which will satisfy the needs of all significant groups," that is, to depend upon a variety of projects to produce final results, but to provide a uniform base of raw material, or preliminary listing and sorting upon which the specialized projects may draw. We at the library look closely at our costly and time-consuming operations to see whether the base for further refinement which we hope for is really being established. Our large staff of descriptive catalogers costs a great deal of money, and we have so far acted on the assumption that their efforts were essential and the expense inevitable. The union catalog has been a great enterprise, but it has not yet literally solved the problem of locating in some American library at least one copy of every important research book, for this it cannot do until it is literally complete, and until the gaps which it reveals have been filled in. Our public catalog, made so carefully, still does not simply and unerringly reveal the true complete content of the library, including periodical literature, on any topic, but continues to answer questions with riddles.

We have become concerned about bibliographical planning in connection with great projects outside the library. The Bibliographic Index, concerning the development and value of which there is a certain difference of opinion, is apparently now limited to material which can be inspected for assignment of subject headings in New York City, and yet this is the only tool of its kind. A survey has revealed 243 indexing and abstracting services, and for all of this intensive effort there is still widespread complaint that the periodical literature of the world is irregularly and incompletely covered. Demands are made upon us either for a complete subject bibliography or for selective reduction of the mass of potential material, and we are again and again faced with the choice between a laborious committee-approved bibliographical compilation or an answer, perhaps to an important inquiry, that so far as we know there is really no adequate tool available. This sort of thing happens all over the world, and it is only in certain fields where special interests have poured vast sums of money into reference media, as chemists or the legal profession or, for instance, the nickel industry have done, that any really satisfactory degree of control has been achieved. We look to these and other specific accomplishments, however, for a kind of guid- 
ance which stirs our imagination and both technically and ideologically may point the way. We have a great measure of bibliographical control. We have trade lists and national lists, a constant stream of bibliographies and bibliographies of bibliographies. We have, if you will exempt the details, a pretty widely accepted system of recording bibliographical items, of cataloging, and of citation. In some slow but sure way it has become the almost universal practice to provide books with title pages for identification, and to gather books together into libraries. We have come a long way. But we have a long way to go, and we wonder whether we are going about it as effectively as we might if all the facts were known.

One phase of our discussion at the library reached an important turning point at our decision to issue the Cumulative Catalog of Library of Congress Printed Cards, the details of which have been given in the announcement issues of the Processing Department's Cataloguing Service bulletins for last November and December. A review published in the Library Journal last May 15 says :

It seems only reasonable to term the new publication one of the major forward steps in centralized cataloging in the United States since the inauguration of printed card sales near the turn of the century. ... Methods of bibliographic description can now be standardized and simplified. Those who dream of printed book catalogs replacing cards in future libraries now have a new tool with which to experiment, while the goal of complete centralized description and location of the bibliographic resources of the nation can now be measureably nearer.

We would never have taken a step of this sort without the careful consideration with which many of you have come in contact and without the conviction that we were on the right track. So far, professional opinion has supported our confidence.

\section{L.C. Card-Production}

* By definition, the Cumulative Catalog reproduces, so as to provide an additional means of distribution, the cards originally produced for cataloging purposes within the library. Certain modifications, in fact, in the design and mechanical handling of cards have directly resulted from the method of producing the Cumulative Catalog. Taken altogether, card production is bibliographically probably the library's most important enterprise, and the one which has had the greatest effect upon the practices of other libraries. There are still innumerable questions of detail to be settled, and every thoughtful and technically skilled cataloger engages in differences of opinion with the Processing Department. Yet we can point to a group of techniques and an embodiment of plans which may be said not only to have worked, within the scale originally contemplated, but to have survived enormous expansion in scope. The making of cards, moreover, is the operation which technical librarianship has carried to the greatest refinement, and consequently, is the point upon which the greatest intensity of discussion in relation to the importance of the detail involved can be aroused. However, excepting for the various services such as the Engineering Index which issue their material in card form, most card production has been conceived in terms of the needs of individual library catalogs. While a number of international codes have been proposed for adoption, it seems to us that insufficient thought has been given to card production as the first step in international bibliographical control, the raw material upon which subsequent operations rest. So our discussion has often started on the issue of how far the card-producing activity of the library should be carried and whether it is possible to achieve an expanded coverage with cards made according to present standards. Our thinking ahead leads us to base our plans on existing accomplishments.

We should not limit our thinking ahead to the original intention of producing highstandard card catalogs for our own use and giving other libraries a chance to benefit by the work. It has already become more tian that. A great many bibliographical projects are based upon a review of proof sheets issued during the production of cards. Fundamentally a card is a one-item bibliography, the original record, the point where all other bibliographical operations begin, for even lists are usually made from slips or rudimentary cards. In one way or another we have become responsible for a supply of bibliographical raw material, and, to the considerations of accuracy, reasonable consistency, profes- 
sional workmanship and availability, we must now add that of complete coverage. We must consider whether uniform card production covering the entire national output of recorded knowledge, from a certain year onward, does not underlie all major projects for selection, analysis, and bibliographical control. In this concept, cards are not intended solely for catalog purposes, but also, because they can be manipulated, for sorting for bibliographical purposes. To what extent is bibliography handicapped by the fact that for the United States there is no complete listing of the entire mass of raw description in a form which can be physically broken down as a starting point for particular projects? The most obvious answer is that coverage of this sort for one nation's output even if it could be achieved, is not going to give us subject coverage, which does not follow national lines. But just as selective lists of subject references must be based on complete lists from which the unnecessary matter is discarded, so the complete subject lists must be based on more inclusive lists of production, probably in national units.

I am intentionally discussing card production before book-form national bibliography because of our conception of a national bibliography, not only as a list of bibliographical items published, but also as a list of descriptive cards introduced into the bibliographical machinery and available. Direct production of a book-form catalog, while it might have typographical advantages, seems to us less of an accomplishment than one operation which produces both cards for sorting and books for distribution, checking, and reference. After exhaustive inquiry and experimentation, the Processing Department evolved the method of reproducing the cards in book form by photooffset which we now feel has such promise.

Should the fact that we cannot hope to produce descriptive cards for the whole world's yearly output delay us in trying to provide the basic inventory for the United States, if that much is within our power? The national unit is a very logical unit, and one which practically every planner has used.

Herbert Putnam, writing on the future of the Library of Congress in Emily Miller Danton's The Library of Tomorrow, published in 1939, calls attention to the 6,000 regular purchasers of the cards prepared by the library and goes on to say that the "fullness and scholarly accuracy of the entries on these cards requires so much labor that the output cannot begin to keep pace with incoming material. Ideally, this service should constitute a central cataloguing bureau for the entire country but, actually, it falls far short of doing so. To achieve this ideal a larger staff of cataloguers is needed as well as a larger appropriation for printing and distribution of the cards and for the acquisition of books." Great improvements have since been made in the degree to which cataloging keeps pace with incoming material, particularly with the inception of cataloging by the Copyright Office, and various phases of the cooperative cataloging program have extended the scope. John Shaw Billings, in his presidential address to the American Library Association in 1902, spoke as follows:

I think it well, however, to remind you of your duties to this your national library, and especially that the librarian of every city, town, or village in the country should make it his or her business to see that one copy of every local, noncopyrighted imprint, including all municipal reports and documents, all reports of local institutions, and all addresses, accounts of ceremonies, etc., which are not copyrighted and do not come into the booktrade, is promptly sent to our national library.

The current tendency is not to propose that all of the needed cataloging work should be done at one place because of the great difficulty of physically assembling it, but rather to suggest that librarians must "see to it that the cataloging and bibliographical work is done by the whole library community and by others engaged in the similar work of placing important facts under current fingertip control."

In the first place, can we accept the thesis that it is desirable that a specific group of libraries should, taken together, acquire the entire United States output year by year, and that their cataloging efforts taken together would thus produce cards for the entire national output, which, if gathered together and published in annual volumes with cumulations, would constitute a desirable system of national bibliography.?

In the words of the recommendation of the Library of Congress Planning Committee, the library is urged, as part of its leadership 
in cooperative movements, and as part of its share of the national library program on behalf of nonfederal libraries and of individuals who are not federal employees, to undertake "... the printing at regular intervals of as complete a list as possible of publications currently published in the U.S. . .."

The Conference on International Cultural, Educational, and Scientific Exchanges, held at Princeton, N.J., Nov. 26, 1946, recommended that:

... UNESCO and other suitable agencies and groups, governmental and nongovernmental, encourage national governments, national library associations, and other agencies in every country to see to it that there is published for each country a current national bibliography, which will include in an author arrangement under broad subjects, in one or more sections or parts, the following types of material, listed in the order of importance:

a. Books and pamphlets in the book trade

b. Government documents at all levels

c. Nongovernment periodicals

d. Newspapers; and, if possible:

e. Miscellaneous publications

f. Motion pictures, including news reels, documentaries, instructional films, and photoplays.

We believe there is a place and need for both selective and comprehensive national bibliographies, but because of their fundamental importance we recommend that priority be given to effecting arrangements for securing bibliographies of the comprehensive type.

It is recommended that the Library of Congress should formulate and present to A.L.A., A.R.L., S.L.A., and other library associations in this country, for their comment and criticism, plans for editing and publishing a complete current national bibliography of the United States, involving as may be necessary the coordination of existing efforts in this field, such as the catalogs of the Superintendent of Documents, the Monthly Checklist of State Publications, Cumulative Book Index, Catalog of Copyright Entries, and other sources, and looking to the coverage of fields not now covered, such as municipal documents, house organs, etc.

Subsequent action, following up the Princeton recommendations, taken at an informal meeting held in the Library of Congress on Jan. 22, 1947, resulted in a commitment that the library would present.a plan for a national bibliography at the San Francisco convention of the American Library Association.

The Assembly of Librarians of the Ameri- cas which has just been meeting at the Library of Congress included in the recommendations of its Committee on Education for Librarianship "that steps be taken to organize as soon as possible the bibliographical patrimony of each country in accordance with the latest requirements of library science and utilizing appropriate practices and techniques;" and in the recommendations of its Committee on Bibliography that "in view of the circumstance that repeated recommendations of international organizations concerning the desirability of publishing national bibliographies have not been heeded except in a few countries...., national libraries or bibliographical institutions be charged with the duty of bringing to fruition the compilation and publication of national bibliographies of their respective countries, where such work is not already being realized either commercially or by government agencies."

The recommendation of the Princeton Conference does not clearly state that this plan must necessarily involve a single publication or a new one, and it implies nothing one way or another on the effect which a full material bibliography would have on lists now current which would be duplicated in part. All of the existing lists have a distinct function to fulfil, and the library proposal to expand its card-producing facilities and its Cumulative Catalog to a point of all-inclusiveness seems to us in no way to interfere with any of the existing publication programs of more restricted scope and perhaps greater usefulness. If our inquiry were directed at the publication of the national bibliography alone, we might well explore the question whether the Cumulative Book Index, the Catalog of Copyright Entries, the Monthly Checklist of State Publications, the Monthly Catalogue of U.S. Public Documents with other standard lists, taken together, constitute an approach to national bibliography, and that all that is needed is a supplement which would list publications not included in any other list. But the established major lists are themselves parts of a pyramidal structure from which the apex is lacking. There are other more partial lists of publications of particular agencies of the government, from which the entries are repeated in the Superintendent of Documents' inclusive list. Last March the 
Congressional Joint Committee on Printing approved a resolution eliminating the biennial catalog of government publications, on the theory that the essential purposes could be accomplished by the monthly list and annual index. The Superintendent of Documents also issues selective lists, such as the 46-page One Hundred Selected Books Now Available ... published in 1946. And there is no list which literally covers the entire output of the federal government, including material, often of great value, processed independently by the various agencies. The New Hampshire State Library, the Maine State Library, and the Universities of North Carolina, Arkansas, and Florida are issuing lists of material for their respective states. The California State Library covers bibliographically the publications of California municipalities, and the municipal reference library in Chicago has likewise undertaken a local bibliographical function. Jerome Kear Wilcox' Manual on the Use of State Publications and the lists on state documents published every other year in Special Libraries are but two of the items in what is already a fairly complex bibliography on the listing and availability of our national output. We have not yet actually tried to make a list of current bibliographies which, taken altogether, would indicate everything issued in the United States, and this should be a part of a fully-developed attack on the problem, but that list would be sufficiently long to show that literally complete national bibliography involves more than a few convenient reference tools. Moreover, as already suggested, the approach to complete national bibliography through use of a number of existing lists takes no account of that desirability of producing at the same time the same information in card form for a variety of subsequent bibliographical projects; whereas an approach which takes the Cumulative Catalog of the Library of Congress as a base would cover such a provision.

Our tentative plan, then, of developing the Cumulative Catalog into a national bibliography is in line with the recommendation of the World Congress of Libraries and Bibliography held in Rome in 1929, which, at its fourth session on international projects, "notes the need of an adequate national bibliography and recommends that each country publish its national bibliography in such form that cards for the entries may be filed for reference." So far as our plans have been worked out theoretically, this involves two steps :

a. To expand the card-producing facilities of the library to cover more and eventually all the United States material and more and eventually all kinds of material, and

b. To divide the annual and, if decided upon, five-year issues of the book-form Cumulative Catalog into two parts, the first limited to United States imprints of the previous year and the second to contain all other entries, that is, foreign and earlier United States imprints.

\section{Increased Attention to Nonbook Forms}

While books, pamphlets, and periodicals are still the major concern of libraries and still the unquestioned leading media of recorded communication, libraries generally, and particularly the Library of Congress, are gradually giving increased attention to nonbook forms such as maps, some of which are already listed in the Cumulative Catalog, motion pictures, as noted in the Princeton recommendations, sound recordings, in which we have an important development, and music, for which our Copyright Division now prepares individual cards for some 14,500 published items a year. If the function of a national bibliography is, among other things, to serve not only as a medium for verification in cataloging books but as a checklist of all material which conveys knowledge or information or reaction of any sort, should we not logically break completely the barrier between published print for reading and other forms of communication, and draw the line only at publication, validity, and continuity? I use this word "continuity" in order to exclude photographs and other single images, sounds, or words, but include any series of such elements which involves a sequence in time. Adequate discussion of this line of demarcation, or attempt to define publication, validity, or magnitude of time element, while probably necessary at some stage, had best be avoided here, as it would certainly lead too far afield into academic minutiae, and the definition, in the end, would doubtless have to rest upon flexible conventions. But we have already gone far enough in this direction to recognize films, phonograph records, commercial advertising matter of many kinds, dia- 
grammatic material, radio programs, anything, in fact, regardless of form or medium, as contributions to knowledge and records of our time which,, on an equal footing with publications in the usual sense, deserve bibliographical recording to assure their availability and use. On this tentative assumption, we shall use the words "publication" or "material" or "current U.S. output" in this wide sense in the remaining passages of this paper.

If cards are to be issued at the Library of Congress for all of this material made available in the United States, does this necessarily mean that the material must itself come into the library? And if it does not, can we satisfactorily undertake the production of cards based on copy contributed, without seeing the material itself? The first reaction is likely to be a strong negative, but in view of the amount of confident bibliographical transcription which is constantly and successfully carried on, we wonder whether this distrust of all but firsthand inspection is wholly justified, and the issue is of such crucial importance that we think it deserves the most careful exploration before this prospect is rejected. Might it be practical for the library to produce, in expansion of its present cooperative cataloging arrangement, two kinds of cards:

a. Cards of the same fullness as at present, continuing present policies, for material added to the library or, to the relatively slight degree that current United States publications are involved, for material covered by copy sent in for cooperative cataloging by other libraries under the present agreements.

b. Cards which can be distinguished from preceding category in some way, without subject headings, without classification, and without unverifiable added entries and descriptive detail, to be distributed in a different way and at a different rate, for books known to the library only from lists available or contributed by cooperating local and special libraries, but still made as well as possible.

Obviously the theory advanced here is that coverage is, for the total bibliographical problem, more important than perfectionism, that raw material for further bibliographical refinement at the evaluation stage should be turned out rapidly and cheaply, and that total omission, assuming our conception of an all- inclusive national bibliography, is worse than the omission of, or even error in, descriptive detail. Our precautionary measure is that unverified cards should not be confused with final cards. The greater danger is that insuperable difficulties might be met in working out a system for nonduplication of effort. It is in this connection that cataloging at the source, since there is likely to be but one source and many points of distribution, at the moment of issue, by collaboration between the publisher and the library profession, may, in the long run, not prove so impractical as has been assumed. The libraries which would undertake to supply copy would be those which, taken all together, cover the whole output of the United States and are sufficiently convinced of the importance of the larger bibliographical issue to contribute in this way to the general good, just as the national library might contribute by printing cards for books which it never receives. The alternative would be to add everything to the Library of Congress, a possibility which seems to us now as the less realistic of the two.

Another phase of the problem is whether the Library of Congress Card Division could reasonably be expected to stock such a cumulation of cards, or whether there is some promise in experiments recently conducted by the Processing Division to hold and stock the transparencies from which cards in lesser demand can be printed photographically on order. This would apply particularly to cards for the nonbook materials and lesser publications based on cooperative copy. It seems to us reasonable to stock cards on which average demand may be anticipated as at present, but to print a lesser quantity of the additional cards proposed, and hold a master transparency against the possibility of further photographic reprinting if demand requires. But the complete output would be available to regular subscribers both as cards and as proof sheets, for the expanded national part of the Cumulative Catalog, and potentially available for a promising innovation in bibliographical sorting over and above the needs of our own subject cataloging.

There has been talk of providing behind the scenes a variety of bibliographical files in part for the use of the compilers of bibliographies who might use them personally, but 
more importantly as a source of high-speed photographic reproductions of subject sections of the catalog, an operation which cannot well be performed by withdrawal of cards from the public or other permanent catalogs. Sorting for this purpose might go further than the filing of cards in classified order according to their assigned shelf numbers or alphabetically by their assigned subject headings. There might be classifications by geographical areas covered (as distinguished from alphabetical place names), by chronological periods covered, by materials or things, by concepts or ideas, and by the activities of man, all designed to bring together scattered subject headings in a different arrangement, all in addition to the traditional classification by fields of knowledge, and all following upon experiments in classification carried on by many organizations concerned with the collection of references in classified order rather than the arrangement of books on library shelves. There might also be sortings according to publishers and places of publication, by form and by treatment (e.g. textbooks or historical fiction) as well as by date of publication. In such a bibliographical operation, we might have to file subject cards without hesitation for material which we had never seen. In a very high percentage of cases there is adequate indication of content for rudimentary sorting in the title itself, and in a device of this sort, intended to put into bibliographers' hands mere raw material for their further individual use, there is a justifiable margin of surmise which should be absent in the actual cataloging of a library.

\section{Subject Approach Analyzed}

If the national bibliography were to be truly all-inclusive in the coverage of the output, there is little question but that it should list periodical articles individually. It is at this point, however, that we must try to be practical. There is another way. In the subject approach, we should not try to do everything with one list, but depend rather upon developing a series of existing services so that they may together cover the field. Author listing and basic inventory, even on the scope which we have suggested, would benefit greatly by the uniform treatment of an all-inclusive national bibliography, because the listing can be defined accurately and, taken in units of nations and years, can be done, if done inclusively, once and for all, leaving only relatively minor technical difficulties and the inconvenience of reference to many volumes. But that is a bulky but orderly reflection of a massive production which we are trying to increase rather than suppress. To subject bibliography, however, there is no definable end, no consistent national or annual limitation, no reliable or even desirable uniformity of interpretation, and a great desire to reduce the mass selectively. The eventual ends of subject bibliography are best served not by a single system, but by a great number of successive individual efforts, varying according to points of view, critical skill, and application. The services are but an intermediate step between inventory and critical selection. If the services themselves are selective, where lies inclusive subject coverage? If progress can indeed be made in improving the coverage and coordination of the indexing and abstracting services, may we hope that they would undertake the generalized subject approach, not only to periodical material but to the content of books and related nonbook material as well? Could they do this if the library's bibliographical services can find ways of making the material available to them? And in exploration of this possibility, would not the availability of cards from the special sortings just described be the most valid approach? It occurs to us, too, that one of the most potentially fertile applications for punched cards as aids to bibliography is control of what material has been indexed and abstracted in which services, rather than control of the subject content itself. Cards which can be read visually but which can be routed or distributed from a center mechanically according to coverage formula could do a great deal to decrease undesirable overlap and increase coverage to journals not ordinarily indexed by a given service. It would then become very important to know completely from the inventory what the composite works subject to indexing are.

\section{Complete Bibliographical Control?}

I have been trying to indicate that our thinking about national bibliography has been in the direction of considering it as an element in the achievement of complete biblio- 
graphical control rather than as an isolated publishing project. Bibliographical control has not meant to us the achievement of a system whereby any inquiry, however vital, however new, however personal, or however imaginative can immediately be answered by a selective analysis ready-made by some other specialist who has anticipated this demand. That may be what we ought to lead up to, but we must approach it in gradual stages, for perfection of control lies at the end of the trail, the ultimate objective of intellectual inquiry. We have thought of national bibliography and card production as important elements in providing the foundation upon which may be based extremely varied bibliographical compilations undertaken by others, perhaps, by other offices of the libraries themselves, and directed at the needs of special branches of science, special groups of scholars, and special levels of inquiry.

We ask you as the library profession whether you think we are proposing one more publication to do what a combination of existing publications will do as well, whether the production of one national bibliography, even in view of the large number of national bibliographies currently produced in other nations, would really be a step toward coordinated control. We ask you whether an undertaking of this magnitude should be conceived as self-supporting, and if so, what you think its chances are. We need advice on whether we are justified in suggesting the amount of cooperation involved in supplying copy, and whether the net result would be a national service eventually appreciated or an undesirable attempt at centralization, in which there may be some danger of principle involved.

We ask ourselves whether we are being realistic in considering plans of this sort without so much, at this stage, as calculating costs. We ask ourselves what bibliographical interpretation of leadership we ought to place on our position as the national library, and whether we are turning in directions already exhausted as fantastic wishful thinking, or whether we are logically developing the continuation of operations already begun and to which we have committed ourselves at this time.

\section{Attack at Various Levels and Stages}

I am very much impressed by the general spirit of Paul Vanderbilt's paper, and by that of Dr. Evans's introductory note. It is obvious that the solutions eventually found must be realistic and realisable; but I am sure that it is a mistake to approach so great and urgent a problem from the point of view of what is immediately attainable with existing resources. We have to find the ideal solution and then reduce that solution to practicable form. If there is anything certain in this field it is that fragmentary solutions will only aggravate the present condition of affairs. It should no longer be necessary, for instance, for individuals to attempt enterprises which should be undertaken by cooperative effort.

I had hoped to be able, in response to your request, to offer considered comments on this whole problem of bibliographic control, but it is difficult to find an opportunity for consecutive thought during the Mexico City conference of UNESCO. May I, therefore, hastily throw out a general suggestion? It appears to me that the problem of bibliographic con- trol should be tackled at various levels and in various stages. The complete listing of the entire intellectual production of mankind is needed only for purposes of inventory. I suggest, therefore, that there should first be compiled such national inventories, by daily bulletin where necessary and practicable, and split up by form, possibly in the six groups proposed by the Princeton conference of 1946 . Such an inventory would be most useful in book form.

Immediately on this complete inventory should follow a first process of selection, by the production of national bibliographical listings, from which the obvious rubbish and ephemera have been eliminated. This bibliography, which should in the first place be in card form, would form the basis for the next stage, which would be a rearrangement of the bibliographic cards, after a further process of exclusion, in subject and classified form, both national and international. A further process of selection, together with much critical effort, would produce the fourth stage, that of international abstracts by wide sub- 
jects. Finally (in the contemporaneous sense) would come the critical survey of the year's work in particular disciplines.

In the United States such a structure already exists in large part. The Catalog of Copyright Entries could be converted into the national inventory; the L.C. Cumulative Catalog could be divided into national and foreign sections, the first part forming the national bibliography; and so on.-Theodore Besterman, chief, Documentation, Library, and Statistical Services, UNESCO.

\section{Federal Documents}

The proposal by Paul Vanderbilt poses a solution for achieving a comprehensive national bibliography. Can the Cumulative Catalog of the Library of Congress achieve this result in the field of government publications? What is involved in such a project? The Monthly Catalog of U. S. Government Publications, issued by the Superintendent of Documents, now contains over 20,000 entries annually. It includes printed and processed periodicals, serials, and separates. Although since January 1936, it has included processed publications, it has never been comprehensive in their coverage. To date, no effort has ever been made to include printed and processed publications of field agencies. Although the Monthly Catalog has for some time indicated Library of Congress card numbers at the time of publication, one finds only a small percentage of the entries with Library of Congress card numbers. The natural assumption would follow that at present only those items with L.C. card numbers would have been in the Cumulative Catalog. This raises the question whether there should be an L. C. card for every federal government publication. The problem is really larger: namely, should any library's catalog contain a card for every federal publication in its collection? The answer should be definitely "No," especially in the case of small pamphlets. Complete analytics for the contents of each series should also be discouraged. We need comprehensive and as nearly complete as possible periodic bibliographies of government publications at the national level, but why make them part of the Cumulative Catalog? The responsibility for coverage in this field should be the Superintendent of Documents, who is charged with this function, and all federal publications should be omitted from the Cumulative Catalog. This policy would eliminate duplication and enable the Library of Congress to continue its pres- ent policy of printing cards only for the important documents. It is also suggested that the Library of Congress discontinue analytics for most of the publications in series, allowing such analysis to be made only in the Monthly Catalog.

Judging from the lack of inclusiveness in the Monthly Checklist of State Publications, I have serious doubts as to whether the $\mathrm{Li}$ brary of Congress should undertake to cover an equally large or larger field such as federal government publications. Since already the Office of Superintendent of Documents has the background of knowledge and the facilities, it should undertake the really comprehensive catalog of federal publications. As a matter of fact, just such plans are under way in this office. The first step was taken when the decision was made to abolish the Document Catalog and concentrate all efforts on the current periodical catalog, the Monthly Catalog. Just as a matter of record here, it might be well to state that, if the Document Catalog had been continued for the next biennium, I94I-42, it would have repeated over 45,000 entires already noted in the Monthly Catalog, with the addition of only 2,000 new items now published in the first supplement.

Beginning September 1947 the new format of the Monthly Catalog is that which is found in any library card catalog, with one exception: the alphabetical arrangement is under inverted author headings. In addition to all agencies being arranged in alphabetical order, all publications for each agency are in alphabetical checklist order, separates and series titles, with contents, being all in one alphabet. Furthermore, a more complete subject analysis is now planned each month in the index, and more direct reference is secured by reference to entry number rather than page. About the first of the year 1948, the office plans to begin and to continue a 
systematic effort to secure from all federal agencies, both $W$ ashington and field, all their publications, either processed or of nonG.P.O. imprint. When this program is completed, we shall have, for the first time, a comprehensive catalog of U. S. government publications nearing completeness in scope.

With the change in arrangement in the Monthly Catalog itself, libraries can very definitely eliminate a tremendous amount of unnecessary analytics for publications issued in series. Henceforth, all library catalogs need only record series by titles of the series, securing analysis of the contents of the series through the Monthly Catalog. Furthermore, all small pamphlets and other ephemera can be systematically arranged by issuing agency, and the references can be secured to them by subject and author through the Monthly Catalog.

\section{Re State Publications}

The question of the inclusion in the Cumulative Catalog or in any other tool, of a complete list of all the publications of the forty-eight states and the territories and insular possessions, poses a real problem for solution. Unfortunately, the title, Monthly Checklist of State Publications, now issued by the Library of Congress, is misleading because actually the bibliography has never been more than an accessions list of state publications received in the Library of Congress. Furthermore, very few comprehensive lists of publications have appeared in any of the states, either cumulative or on a current periodical basis. Strangely enough, only a few of the state libraries, either now or ever, have issued periodic checklists of their state publications. At the present time the state libraries of Maine, New Hampshire, New York, and California do so. In the cases of Wisconsin and Minnesota, historical societies have prepared periodic lists. Such lists have also been recently regularly prepared by the state universities of North Carolina, Florida, and Arkansas.

Only one state, California, has a centralized state document distribution statute, one of the provisions of which is the issuing of a comprehensive quarterly list of California state publications. While it is true that every state has many statutes calling for some distribution of its publications, even includ- ing, in many cases, the Library of Congress, no one officer is charged with the responsibility of this distribution. In a sense, state, city, and county government publications are local imprints of the state, as are books and pamphlets published by small printers and publishers within the state. A national agency such as the Library of Congress cannot expect all publications published within state borders to come to it because of a state statute prescribing such action. Securing state imprints, including state and local government publications, requires at least one representative of the national agency in each state or possibly a regional representative to visit systematically all agencies many times during the year in order to secure their publications. Should not the state library or the state university library assume this function in each state? Furthermore, should it not also supply the master catalog card for each state imprint? This project is not only one of listing and cataloging but also of collecting, and therefore cooperative efforts are most essential. If this were done, the Monthly Checklist of State Publications would be far more complete than is now possible. Complete separation of this checklist without duplication should be made.

\section{City and County Documents}

At the present time systematic listings of publications of government agencies lower than the state level, such as city and county documents, are almost nonexistent. Such listings are available for only New York City, Chicago and Cook County, and California cities and counties. The New York City list and the combined Chicago and Cook County list are prepared by the Municipal Reference Library in each city. The California publications are to be found through an accession list of city and county publications received by the state library, which is published by that library in its "News Notes" of California library. Furthermore, it is doubtful whether many libraries throughout the country have nearly complete collections of their local city and county publications. It would, therefore, appear that the success of such a project would be dependent upon the cooperation of every library in the U.S. Here we appear to be in the realms of Utopia. 
As soon as bibliography for government publications becomes comprehensive or complete, libraries should save considerably in their annual cost of cataloging. Such bibliography should adequately cover contents of all publications issued in series and thereby eliminate costly analytics completely from the card catalog. Furthermore, it is conceivable that all document cataloging might be eliminated in favor of this type of bibliography. The author section of the bibliography could be checked for all items as received, and the entire collection bound and arranged on the shelves alphabetically by state, then by issuing agency, and finally, by title. Therefore, could libraries not well afford to contribute their savings in cataloging costs to such a national bibliography? The success of a project of such magnitude will require substantial financial assistance from libraries or a permanent grant from some educational foundation or both. Furthermore, with the successful promotion of such a project, a library not only can reduce its cost of cataloging but can also substantially reduce the permanent size of its public catalog by excluding government publications from it entirely. Comprehensive or complete biblio- graphical coverage in book form can materially reduce the size of the public catalog. in any field where author, title, and subject are treated in the bibliography.

\section{Summary}

To summarize briefly, checklists of government publications at the national level now exist for federal and state publications. Present plans for the Monthly Catalog of United States government publications should make it adequate. Suggestions made above should make the Monthly Checklist of State Publications include what its title indicates. Publications of local governments (city, county, school districts, townships, etc.) present a virgin field for checklists. They are not even available at the state level, let alone the national level. With over 3,000 counties and many times that number of cities in the United States, who has the courage to tackle a current periodical checklist? A beginning might be made by including only cities and counties of 100,000 population and over. The ultimate solution of this problem would undoubtedly be checklists of local government publications at state levels.-Jerome K. Wilcox, chairman, A.L.A. Committee on Public Documents.

\section{Municipal Documents}

Mr. Vanderbilt's statement of the basic principles involved in our national bibliographic control in the United States is most illuminating. He seems to have raised all the vital questions concerning such control and his discussion of them is to the point. I find myself in agreement with him and the Library of Congress in its thinking on these proposals.

These are his points that I would emphasize :

I. Our problem is ... to provide a uniform base of raw materials, or preliminary listing and sorting upon which the specialized projects may draw.

2. Card production is the first step in national and international bibliographic control, the raw material upon which subsequent operations rest.

3. To the considerations of accuracy, reasonable consistency, professional workmanship, and availability we should add that of complete coverage.

4. The national unit is a very logical unit.

5. After exhaustive inquiry, the method of reproducing cards in book form by photo-offset was evolved by $L$. of $C$.

6. The current tendency is not to propose that all of the needed cataloging work should be done at one place.

7. A list of current bibliographies (services which are continuous and reliable) should be a part of a fully developed attack on the problem.

8. Cumulative Catalog of the Library of Congress would be the logical base for a national bibliography as desired.

9. The tentative plan of developing the Cumulative Catalog into a national bibliography, involving two steps as outlined, seems very reasonable and workable.

Io. The libraries which would undertake to supply copy would be those which, taken all together, cover the whole output of the United States and sufficiently convinced of the impor- 
tance of the larger bibliographic issue to contribute in this way to the general good, just as the national library might contribute by printing cards for books which it never receives.

The last point is the crux of the entire proposal. And the success of such a national plan would depend on full cooperation of the many libraries to be involved. I find myself believing that such a production of one national bibliography is a step toward coordinated control and that if the idea can be sold to those who are to be involved in planning it and executing it, then present costly bibliographic undertakings will gradually conform to the larger new proposal, and help in financing it, and that it would within time become self-supporting.

In work with municipal documents, the fact that practically all such documents have never been copyrighted, made it apparent to librarians years ago so that Dr. Billings in 1902 reminded librarians of the necessity of supplying such documents to the Library of Congress.

We of the New York Municipal Reference Library immediately upon establishment in 1913 took cognizance of the importance of the city's documents and collected full sets from the time of the records of New Amsterdam in I653 to date. Feeling that we had a responsibility to other libraries of the country to make known what documents were published by the city, and since we were located at the source, the New York Municipal Reference Library began publication of its "Monthly List of New York City Publications" in 1916 and it has been issued regularly, and without a single interruption from that date to the present, a period of thirty-one years, printed in the Municipal Reference Library Notes. No other city in the world provides such an accurate and current checklist of its own documents. Yet the Library of Congress in this statement by Mr. Vanderbilt does not mention this bibliographic' source of New York City municipal documents.

Soon after 1920 I felt the lack of any checklists for documents of other American cities; and therefore instigated a cooperative effort through the Special Libraries Association to overcome the lack. The result was a printed volume entitled "Basic List of Current $\mathrm{Mu}$ nicipal Documents" 1923 which was actually a checklist of official publications issued regularly by the larger cities of the country. From that date we have sought the cooperation of all municipal reference libraries in submitting their cities' documents to Public Affairs Information Service which lists them in its weekly service.

Even with continual urging and cooperation on a volunteer basis, this effort in one small segment of a larger national undertaking has not been roo per cent successful; at best, it can not be rated at much more than Io per cent successful.

This experience at a cooperative effort of listing (not cataloging) municipal documents as published in the United States, on a purely volunteer basis, indicates how difficult it will be when applied to a national bibliography and bibliographic control. However, I heartily endorse the principles as stated by Mr. Vanderbilt and should be happy to help in establishing such a worthy national undertaking. It needs the support of all.-Rebecca B. Rankin, librarian, Municipal Reference Library, New York City.

\section{Cataloging Quarterly}

Desirability of a cataloging quarterly to be issued by the A.L.A. Division of Cataloging and Classification will be put to a membership vote at Atlantic City. The prospective editor is Arthur B. Berthold. Information concerning coverage and contributing editors will appear in forthcoming issues of the A.L.A. Bulletin.-Marie Louise Prevost, Chairman, Committee on a Cataloging Quarterly. 